\title{
High positive end expiratory pressure levels affect hemodynamics in elderly patients with hypertension admitted to the intensive care unit: a prospective cohort study
}

\author{
Lili Zhou ${ }^{1,2+}$, Guoen Cai ${ }^{1,3+}$, Zhihui Xu ${ }^{1,2}$, Qinyong Weng ${ }^{1,2}$, Qinyong $Y e^{1,3}$ and Cunrong Chen ${ }^{1,2^{*}}$
}

\begin{abstract}
Background: To study the effects of different positive end expiratory pressure (PEEP) on blood pressure and heart function in elderly patients with hypertension.

Methods: Forty elderly patients above 65 years of age treated with mechanical ventilation were divided into two groups: a control group of non-hypertensive subjects $(n=18)$ and a hypertension group $(n=22)$ patients with essential hypertension. Changes in blood pressure, central venous pressure (CVP), central venous oxygen saturation $\left(\mathrm{SCVO}_{2}\right)$, heart rate, and airway pressure were determined in response to different selected PEEP levels of $0,2,4,6,8$, 10 and $12 \mathrm{~cm} \mathrm{H}_{2} \mathrm{O}$ under SIMV(PC) + PSV mode throughout the study.

Results: In both groups, the increase in PEEP led to an increase in CVP and airway pressure. When PEEP was above $4 \mathrm{~cm} \mathrm{H}_{2} \mathrm{O}$ in the hypertension group, a decrease in blood pressure and $\mathrm{ScVO}_{2}$, and an increase of heart rate were observed. These results indicated that cardiac output significantly decreased.
\end{abstract}

Conclusion: High levels of PEEP can significantly influence changes in blood pressure and heart function in elderly patients with hypertension.

Trial registration: This trial was retrospectively registered, The Chinese trial registration number is ChiCTR-ROC-1 7012873. The date of registration is 10-2-2017.

Keywords: Positive end expiratory pressure, Hemodynamics, Elderly patients with hypertension, Mechanical ventilation

\section{Background}

The number of elderly patients with essential hypertension is increasing annually at a rapid rate worldwide $[1,2]$. Recent data from the National Health and Nutrition Examination Survey indicate that $70 \%$ of older adults have hypertension [3]. Elastic arteries of elderly hypertensives

\footnotetext{
* Correspondence: ccrcgezll@sina.com

† Lili Zhou and Guoen Cai contributed equally to this work and should be considered co-first authors.

'Department of Geriatrics, Union Hospital, Fujian Medical University, Fuzhou, Fujian 350001, People's Republic of China

${ }^{2}$ Department of Critical Care Medicine, Union Hospital, Fujian Medical

University, Fuzhou, Fujian 350001, People's Republic of China

Full list of author information is available at the end of the article
}

dilate and stiffen, which decreases arterial capacitance and limited recoil and is thus unable to accommodate the changes that occur during the cardiac cycle $[4,5]$. Therefore, if cardiac output decreases, the blood pressure drops immediately in elderly hypertensives.

Multiple methods exist for the measurement of cardiac output. However, accurate measurement of cardiac output, such as that obtained using a SwanGanz catheter and cardiac color ultrasound requires advanced instrumentation. Another important factor for hemodynamic stability is the balance between oxygen delivery $\left(\mathrm{DO}_{2}\right)$ and consumption $\left(\mathrm{VO}_{2}\right)$. The most often used bedside parameter to assess the relationship between oxygen 
supply and consumption is central venous oxygen saturation $\left(\mathrm{ScvO}_{2}\right)$ [6, 7]. $\mathrm{ScvO}_{2}$ decreases under low oxygen supply conditions as in occurs during low cardiac output, decreased hemoglobin, decreased arterial oxygen saturation, or in cases of increased oxygen demand that occurs with shivering, fever, agitation, and hypermetabolic state $[8,9]$. Therefore, if hemoglobin, arterial oxygen saturation and oxygen demand are relatively invariant, $\mathrm{ScvO}_{2}$ is associated with cardiac output.

Elderly hypertensive patients have poor cardiorespiratory function and often require ventilator assisted breathing [10]. As far as we know, the elasticity of arterial vessels in elderly patients with hypertension is diminished while the adjustment function of arterial vessels is poor; therefore, hemodynamics is susceptible to external factors such as positive pressure ventilation [11]. If positive end expiratory pressure (PEEP) is improperly used, it may have negative effects on blood dynamics and oxygen metabolism in elderly hypertensive patients, and may even cause multiple organ dysfunction and death [12].

This study aimed to explore the effects of different PEEP levels on blood pressure and heart function in elderly patients with hypertension, and to minimize the adverse effects of PEEP on hemodynamics.

\section{Methods}

\section{Study design}

For all selected patients, the SIMV (PC) + PSV ventilator mode (Vela ventilator, American) was utilized to assist breathing. The tidal volume was controlled (10 $\mathrm{ml} / \mathrm{kg}$ ) to maintain pulmonary oxygenation and promote carbon dioxide exhalation, as well as the

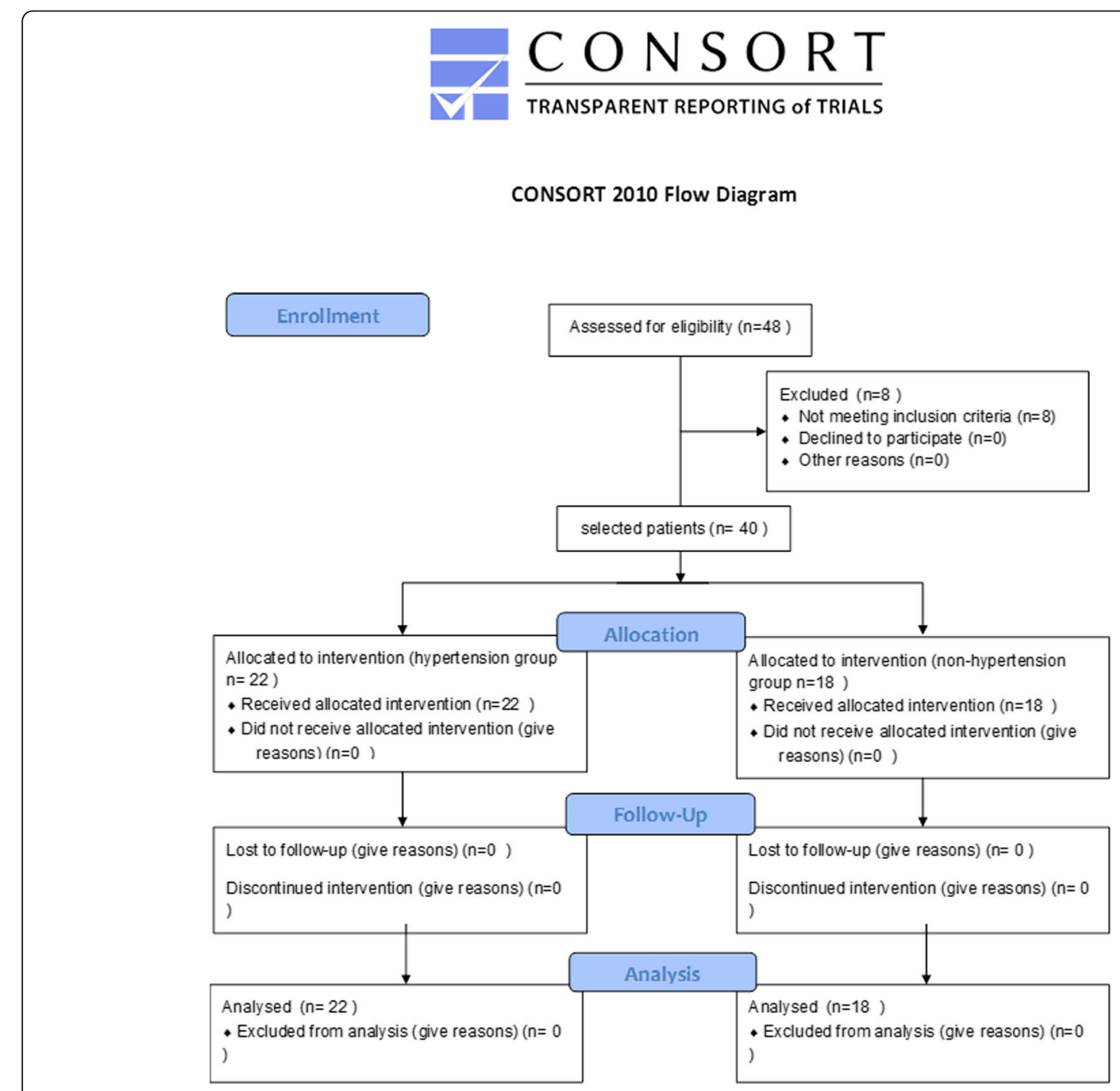

Fig. 1 Consort Flow Diagram 
inhalation time $(1.2 \mathrm{~s})$, and respiratory frequency (18 times/min). Oxygen concentration maintenance at $40 \%$ made the peripheral oxygen saturation more than 95\%. All patients underwent radial artery puncture and subclavian venous catheter. Phlegm was removed from the airway, and subjects were placed at a comfortable $30^{\circ}$ half supine position with infusion speed regulated at $40-50$ drops $/ \mathrm{min}$. Midazolam $0.05 \mathrm{mg} / \mathrm{kg} /$ $\mathrm{h}$ was used to limit spontaneous breathing. Tidal volume was maintained relatively constant, and changes in blood pressure, central venous pressure (CVP), $\mathrm{ScvO}_{2}$, heart rate (HR), and airway pressure were determined in response to different selected PEEP levels of $0,2,4,6,8,10$ and $12 \mathrm{~cm} \mathrm{H}_{2} \mathrm{O}$. Each PEEP level exposure lasted $2 \mathrm{~h}$. The researchers were blinded to patient treatment conditions. If a significant decrease in blood pressure and an obvious decrease of peripheral oxygen saturation $\left(\mathrm{SpO}_{2}\right)$ were noted, the study was terminated to ensure patient safety. No patients withdrew from the study.

\section{Participants}

This prospective, observational study was conducted between January 2015 and January 2017 at the Intensive Care Unit in Fujian Medical University Union Hospital. Chinese clinical trial registration number is ChiCTR-ROC-17012873. Forty elderly patients over 65 years of age with respiratory failure undergoing mechanical ventilation treatment were divided into two groups: a control group of non-hypertension subjects $(n=18)$ and a hypertension group of patients $(n=22)$ with essential hypertension (Fig. 1). Respiratory failure in these 40 elderly patients resulted from pneumonia. All patients or their legally authorized representatives provided written informed consent. The study was approved by the Ethics Committee of Union Hospital Affiliated to Fujian Medical University. We excluded patients with secondary hypertension, shock, arrhythmia, and severe heart failure (NYHA cardiac function grade III - IV).

\section{Lung function and hemodynamic measurements}

To ensure that the subclavian vein catheter (Arrow, American) was located in the superior vena cava, the position of the catheter was confirmed by bedside Xray or $\mathrm{CT}$. The subclavian vein catheter was connected to a multi-parameter cardioelectric monitor (GEcicpro/8000i, American) to measure CVP. Extraction of $1.5 \mathrm{ml}$ central venous catheter blood was used by blood gas analysis (i-stat300 blood gas analyzer, Abbott, United States) for $\mathrm{ScvO}_{2}$ monitoring. In addition, a multi-parameter cardioelectric monitor continuously assessed radial blood pressure, $\mathrm{HR}$, and $\mathrm{SpO}_{2}$. A ventilator continuously monitored peak airway pressure (Ppeak), mean airway pressure (Pmean), tidal volume (VT) and minute ventilation volume (MV).

\section{Evaluation criteria}

Hypertension was defined as systolic blood pressure (SBP) $\geq 140 \mathrm{mmHg}$ and/or diastolic blood pressure (DBP) $\geq 90 \mathrm{mmHg}$ under sufficient sedation during mechanical ventilation without man-machine confrontation and/or the self-reported use of antihypertensive medication in the previous 2 weeks [13].

\section{Statistics analysis}

We determined the sample size for the study using statistical analysis software, NCSS PASS. All data were presented as mean \pm SD or median (interquartile range) as indicated by data distribution tested by the Shapiro-Wilk test. To compare data between groups, a $t$ test, analysis of variance (ANOVA), Mann-Whitney test, or Kruskal-Wallis test was utilized depending on their distribution and number of variables. Correlation was analyzed by Pearson correlation analysis. Confounding factors were controlled by multiple linear regression analysis. Statistical significance was considered at $P<0.05$.

Table 1 Baseline characteristics. Data are shown as mean \pm SD or median (interquartile)

\begin{tabular}{lll}
\hline & $\begin{array}{l}\text { Control group } \\
(n=18)\end{array}$ & $\begin{array}{l}\text { Hypertension group } \\
(n=22)\end{array}$ \\
\hline Sex M/F (n) & $12 / 6$ & $14 / 8$ \\
Age (years) & $78.1 \pm 9.2$ & $74.5 \pm 6.3$ \\
SBP $(\mathrm{mmHg})$ & $119.1 \pm 9.9$ & $151.6 \pm 13.2^{*}$ \\
DBP $(\mathrm{mmHg})$ & $67.4 \pm 5.3$ & $82.0 \pm 12.0^{*}$ \\
$\mathrm{MABP}(\mathrm{mmHg})$ & $84.7 \pm 3.7$ & $105.1 \pm 10.1^{*}$ \\
$\mathrm{Scr}(\mathrm{umol} / \mathrm{L})$ & $68.0(48.5,83.3)$ & $110.4(57.3202 .3)^{*}$ \\
UA $(\mathrm{umol} / \mathrm{L})$ & $163.0(81.5,311.3)$ & $434.5(312.0,509.0)^{*}$ \\
$\mathrm{TG}(\mathrm{mmol} / \mathrm{L})$ & $1.1(0.8,1.7)$ & $1.7(1.0,3.0)$ \\
$\mathrm{TC}(\mathrm{mmol} / \mathrm{L})$ & $3.6 \pm 1.2$ & $3.8 \pm 0.9$ \\
$\mathrm{LDL}-\mathrm{C}(\mathrm{mmol} / \mathrm{L})$ & $2.2 \pm 1.0$ & $2.2 \pm 0.8$ \\
$\mathrm{FPG}(\mathrm{mmol} / \mathrm{L})$ & $7.6(5.4,8.7)$ & $6.5(4.8,9.1)$ \\
$\mathrm{HB}(\mathrm{g} / \mathrm{L})$ & $102.1 \pm 26.0$ & $91.8 \pm 21.6$ \\
$\mathrm{~T}\left({ }^{\circ} \mathrm{C}\right)$ & $37.1 \pm 0.4$ & $36.9 \pm 0.5$ \\
$\mathrm{CVP}\left(\mathrm{mmHg}, \mathrm{PEEP} 0 \mathrm{~cm} \mathrm{H} \mathrm{H}_{2} \mathrm{O}\right)$ & $7.2 \pm 1.2$ & $8.1 \pm 3.3$ \\
\hline
\end{tabular}

SBP Systolic blood pressure, DBP Diastolic blood pressure, MABP Mean arterial blood pressure, Scr Serum creatinine, UA Uric acid, TG Triglyceride, TC Total cholesterol, LDL-C Low density lipoprotein cholesterin, FPG Fasting plasma glucose, $H B$ Hemoglobin, $T$ Body temperature, CVP Central venous pressure, PEEP Positive end expiratory pressure

*: $P<0.05$ 
Table 2 Effect of different PEEP levels on hemodynamics. Data are shown as mean \pm SD

\begin{tabular}{|c|c|c|c|c|c|c|c|c|}
\hline & & \multicolumn{7}{|l|}{$\operatorname{PEEP}\left(\mathrm{cmH}_{2} \mathrm{O}\right)$} \\
\hline & & 0 & 2 & 4 & 6 & 8 & 10 & 12 \\
\hline \multirow[t]{2}{*}{$\mathrm{SBP}(\mathrm{mmHg})$} & 0 & $119.1 \pm 9.9$ & $120.2 \pm 8.4$ & $119.9 \pm 9.2$ & $121.3 \pm 6.6$ & $121.9 \pm 9.4$ & $120.8 \pm 9.2$ & $122.6 \pm 9.1$ \\
\hline & 1 & $151.6 \pm 13.2$ & $152.6 \pm 9.4$ & $154.2 \pm 10.0$ & $146.1 \pm 14.2$ & $142.8 \pm 14.4$ & $139.8 \pm 15.3^{b c}$ & $137.1 \pm 14.1^{\mathrm{abc}}$ \\
\hline \multirow[t]{2}{*}{$\mathrm{DBP}(\mathrm{mmHg})$} & 0 & $67.4 \pm 5.3$ & $68.6 \pm 6.7$ & $67.9 \pm 5.7$ & $69.6 \pm 6.2$ & $70.5 \pm 6.9$ & $69.7 \pm 7.5$ & $69.6 \pm 8.7$ \\
\hline & 1 & $82.0 \pm 12.0$ & $84.1 \pm 11.4$ & $82.5 \pm 12.9$ & $77.4 \pm 13.1$ & $76.0 \pm 12.4$ & $73.3 \pm 13.8$ & $72.2 \pm 11.7^{b}$ \\
\hline \multirow[t]{2}{*}{ MABP (mmHg) } & 0 & $84.7 \pm 3.7$ & $85.7 \pm 4.3$ & $85.6 \pm 4.3$ & $86.8 \pm 4.9$ & $87.6 \pm 4.9$ & $86.7 \pm 4.6$ & $87.1 \pm 5.4$ \\
\hline & 1 & $105.1 \pm 10.1$ & $107.6 \pm 7.9$ & $106.0 \pm 9.7$ & $100.2 \pm 10.9$ & $98.1 \pm 10.4^{b}$ & $95.3 \pm 11.5^{b c}$ & $93.8 \pm 10.0^{\mathrm{abc}}$ \\
\hline \multirow[t]{2}{*}{ CVP (mmHg) } & 0 & $7.2 \pm 1.2$ & $7.4 \pm 1.2$ & $7.6 \pm 1.2$ & $7.8 \pm 1.3$ & $8.0 \pm 1.2$ & $8.2 \pm 1.3$ & $8.4 \pm 1.3$ \\
\hline & 1 & $8.1 \pm 3.3$ & $8.4 \pm 3.1$ & $9.0 \pm 4.2$ & $8.7 \pm 2.6$ & $9.0 \pm 2.9$ & $9.1 \pm 2.8$ & $9.3 \pm 2.9$ \\
\hline \multirow[t]{2}{*}{$\mathrm{ScvO}_{2}(\%)$} & 0 & $68.4 \pm 7.3$ & $68.6 \pm 5.8$ & $69.3 \pm 6.0$ & $69.9 \pm 7.4$ & $71.3 \pm 5.7$ & $70.4 \pm 8.0$ & $72.0 \pm 6.6$ \\
\hline & 1 & $67.3 \pm 8.5$ & $69.3 \pm 8.9$ & $70.8 \pm 7.6$ & $67.8 \pm 5.7$ & $65.3 \pm 6.4$ & $64.0 \pm 5.7^{c}$ & $61.9 \pm 6.2^{c d}$ \\
\hline \multirow[t]{2}{*}{ HR (bpm) } & 0 & $82.6 \pm 12.5$ & $82.9 \pm 12.7$ & $83.3 \pm 12.9$ & $83.8 \pm 13.5$ & $82.1 \pm 13.2$ & $82.6 \pm 13.3$ & $82.7 \pm 12.8$ \\
\hline & 1 & $80.2 \pm 12.5$ & $78.5 \pm 12.2$ & $76.9 \pm 10.4$ & $80.9 \pm 12.7$ & $82.7 \pm 10.7$ & $85.1 \pm 9.8$ & $88.2 \pm 11.5^{c}$ \\
\hline \multirow[t]{2}{*}{ Ppeak $\left(\mathrm{cmH}_{2} \mathrm{O}\right)$} & 0 & $20.4 \pm 4.9$ & $21.5 \pm 4.6$ & $22.3 \pm 4.4$ & $23.6 \pm 4.5$ & $24.6 \pm 4.4$ & $25.7 \pm 4.5^{\mathrm{a}}$ & $27.3 \pm 4.8^{\mathrm{ab}}$ \\
\hline & 1 & $20.8 \pm 4.1$ & $21.8 \pm 4.3$ & $23.3 \pm 4.6$ & $24.6 \pm 5.1$ & $26.1 \pm 4.9^{a}$ & $27.4 \pm 4.8^{\mathrm{ab}}$ & $29.3 \pm 4.7^{7 \mathrm{bc}}$ \\
\hline \multirow[t]{2}{*}{ Pmean $\left(\mathrm{cmH}_{2} \mathrm{O}\right)$} & 0 & $10.1 \pm 2.1$ & $11.1 \pm 2.2$ & $11.9 \pm 2.3$ & $13.1 \pm 2.5^{\mathrm{a}}$ & $13.9 \pm 2.2^{\mathrm{ab}}$ & $15.1 \pm 2.4^{\mathrm{abc}}$ & $16.2 \pm 2.7^{\mathrm{abcd}}$ \\
\hline & 1 & $10.3 \pm 2.3$ & $11.2 \pm 2.0$ & $12.3 \pm 2.1$ & $13.7 \pm 2.2^{\mathrm{ab}}$ & $14.7 \pm 2.1^{\mathrm{abc}}$ & $16.0 \pm 2.2^{\mathrm{abcd}}$ & $17.5 \pm 2.2^{\text {abcde }}$ \\
\hline \multirow[t]{2}{*}{$\mathrm{VT}(\mathrm{ml})$} & 0 & $644.6 \pm 95.3$ & $649.7 \pm 96.8$ & $654.0 \pm 96.1$ & $651.9 \pm 94.3$ & $\underline{642.6} \pm 106.2$ & $646.3 \pm 106.4$ & $645.3 \pm 107.2$ \\
\hline & 1 & $584.0 \pm 119.1$ & $587.0 \pm 118.3$ & $591.1 \pm 114.1$ & $589.6 \pm 115.4$ & $586.9 \pm 117.7$ & $587.4 \pm 116.3$ & $585.3 \pm 117.3$ \\
\hline \multirow[t]{2}{*}{ MV (L/min) } & 0 & $11.7 \pm 1.6$ & $11.7 \pm 1.6$ & $11.8 \pm 1.6$ & $11.8 \pm 1.5$ & $11.6 \pm 1.8$ & $11.7 \pm 1.8$ & $11.7 \pm 1.9$ \\
\hline & 1 & $10.5 \pm 2.1$ & $10.6 \pm 2.1$ & $10.8 \pm 2.0$ & $10.7 \pm 2.0$ & $10.8 \pm 2.1$ & $10.9 \pm 2.0$ & $10.7 \pm 2.0$ \\
\hline $\mathrm{SpO}_{2}$ & 0 & $100.0 \pm 0.0$ & $100.0 \pm 0.0$ & $100.0 \pm 0.0$ & $100.0 \pm 0.0$ & $100.0 \pm 0.0$ & $100.0 \pm 0.0$ & $100.0 \pm 0.0$ \\
\hline (\%) & 1 & $99.9 \pm 0.5$ & $99.9 \pm 0.3$ & $100.0 \pm 0.2$ & $100.0 \pm 0.2$ & $100.0 \pm 0.2$ & $100.0 \pm 0.2$ & $99.9 \pm 0.5$ \\
\hline
\end{tabular}

SBP Systolic blood pressure, DBP Diastolic blood pressure, MABP Mean arterial blood pressure, CVP Central venous pressure, $\mathrm{ScVO}_{2}$ Central venous oxygen saturation, HR Heart rate, Ppeak Peak airway pressure, Pmean Mean airway pressure, $V T$ Tidal volume, $M V$ Minute ventilation volume, $S_{p} \mathrm{O}_{2}$ Peripheral oxygen saturation; 0: Control group; 1: Hypertension group;

${ }^{\mathrm{a}} P<0.05$, compared with PEEP $2 \mathrm{~cm} \mathrm{H}_{2} \mathrm{O}:{ }^{\mathrm{b}} P<0.05$, compared with PEEP $4 \mathrm{~cm} \mathrm{H} \mathrm{H}_{2} \mathrm{O}:{ }^{\mathrm{c}} P<0.05$, compared with PEEP $6 \mathrm{~cm} \mathrm{H} \mathrm{H}_{2} \mathrm{O}:{ }^{\mathrm{d}} P<0.05$, compared with PEEP $8 \mathrm{~cm}$ $\mathrm{H}_{2} \mathrm{O}:{ }^{e} P<0.05$. In the same group of blood pressure, compared with PEEP $0 \mathrm{~cm} \mathrm{H}_{2} \mathrm{O}:{ }^{a} P<0.05$, compared with PEEP $2 \mathrm{~cm} \mathrm{H}_{2} \mathrm{O}$ : ${ }^{\mathrm{b}} P<0.05$, compared with PEEP $4 \mathrm{~cm}$ $\mathrm{H}_{2} \mathrm{O}:{ }^{c} P<0.05$, compared with PEEP $6 \mathrm{~cm} \mathrm{H}_{2} \mathrm{O}:{ }^{d} P<0.05$, compared with PEEP $8 \mathrm{~cm} \mathrm{H} \mathrm{H}_{2} \mathrm{O}:{ }^{e} P<0.05$

\section{Results}

\section{Participants characteristics}

Descriptive characteristics are summarized in Table 1 . SBP, DBP, mean arterial blood pressure (MABP), serum creatinine (Scr) and uric acid (UA) levels of the hypertension group were elevated compared to the control group $(P<0.05)$. There were no statistically significant differences in age, triglyceride (TG), total cholesterol (TC), low density lipoprotein cholesterin (LDL-C), fasting plasma glucose (FPG), hemoglobin
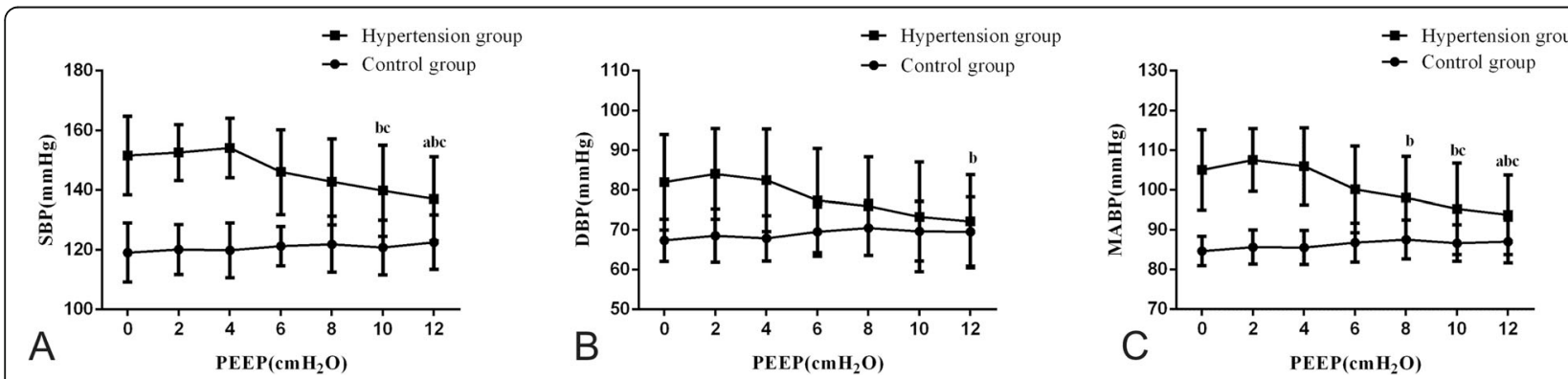

Fig. 2 Effect of different PEEP levels on systolic blood pressure (SBP), diastolic blood pressure (DBP), and mean arterial blood pressure (MABP). a: Effect of different PEEP levels on SBP, $\mathbf{b}$ : Effect of different PEEP levels on DBP, $\mathbf{c}$ : Effect of different PEEP levels on MABP. Data are shown as mean and standard deviation. In the same group of blood pressure, ${ }^{a}$ indicated significant difference $(p<0.05)$ compared with PEEP $0 \mathrm{cmH}_{2} \mathrm{O}$. ${ }^{\mathrm{b}}$ indicated significant difference compared with PEEP $2 \mathrm{cmH}_{2} \mathrm{O}$. cindicated significant difference compared with PEEP $4 \mathrm{cmH}_{2} \mathrm{O}$ 
(HB), or body temperature ( $\mathrm{T}$ ) between the two groups $(P>0.05)$. When PEEP was $0 \mathrm{~cm} \mathrm{H}_{2} \mathrm{O}$, there was also no statistically significant difference in CVP between the groups $(P>0.05)$.

\section{Results per study group Effect of different PEEP levels on blood pressure} In the control group, SBP, DBP, and MABP were unaffected by PEEP $(P>0.05)$. In the hypertension group, when PEEP was below $4 \mathrm{~cm} \mathrm{H}_{2} \mathrm{O}$, blood pressure was also unaffected by PEEP $(P>0.05)$. However, when PEEP was above $4 \mathrm{~cm} \mathrm{H}_{2} \mathrm{O}$, this increase in PEEP led to an decrease in blood pressure $(P<0.05)$ (Table 2, Fig. 2). Moreover, in the hypertension group, when PEEP above $4 \mathrm{~cm} \mathrm{H}_{2} \mathrm{O}$, PEEP was negatively correlated with SBP $(r=$ -0.390, $P<0.001)$, DBP $(r=-0.266, P=0.005)$, and MABP $(r=-0.374, P<0.001)$. Using multiple linear regression analysis to control confounding factors, the results showed that with the increase of controlling factors, the negative correlation between PEEP and blood pressure still existed (Table 3).

\section{Effect of different PEEP levels on cardiac function}

In both groups, an increase in PEEP led to an increase of CVP (Table 2, Fig. 3). Moreover, PEEP was positively correlated with the CVP $(r=0.149, P=0.013)$. With an increase in controlling factors, a positive correlation between PEEP and CVP was still observed (Table 4). In the control group, HR and $\mathrm{ScvO}_{2}$ were unaffected by PEEP $(P>0.05)$. In the hypertension group, when PEEP was less than $4 \mathrm{~cm} \mathrm{H}_{2} \mathrm{O}$, HR and $\mathrm{ScvO}_{2}$ were also unaffected $(P>0.05)$. However, when PEEP was above $4 \mathrm{~cm} \mathrm{H}_{2} \mathrm{O}$, an increase of $\mathrm{HR}$ and a decrease of $\mathrm{ScvO}_{2}$ were observed (Table 2, Fig. 4). Furthermore, in the

Table 3 Multiple linear regression analysis of blood pressure and PEEP

\begin{tabular}{llll}
\hline Hypertension group $\left(\mathrm{PEEP} \geq 4 \mathrm{CmH}_{2} \mathrm{O}\right)$ & Model1 & Model 2 & Model 3 \\
\hline SBP & & & \\
Beta & -0.417 & -0.428 & -0.473 \\
$P$ & $<0.001$ & $<0.001$ & $<0.001$ \\
DBP & & & \\
Beta & -0.277 & -0.307 & -0.341 \\
P & 0.004 & 0.002 & 0.001 \\
MABP & & & \\
Beta & -0.394 & -0.423 & -0.467 \\
$P$ & $<0.001$ & $<0.001$ & $<0.001$ \\
\hline
\end{tabular}

Model 1: Adjustment for age and gender; Model 2: Adjustment for age, gender, triglyceride, total cholesterol, low density lipoprotein cholesterin, fasting plasma glucose, serum creatinine and uric acid; Model 3: Adjustment for hemoglobin, body temperature, minute ventilation volume and peripheral oxygen saturation on the basis of Model 2

SBP Systolic blood pressure, DBP Diastolic blood pressure, MABP Mean arterial blood pressure

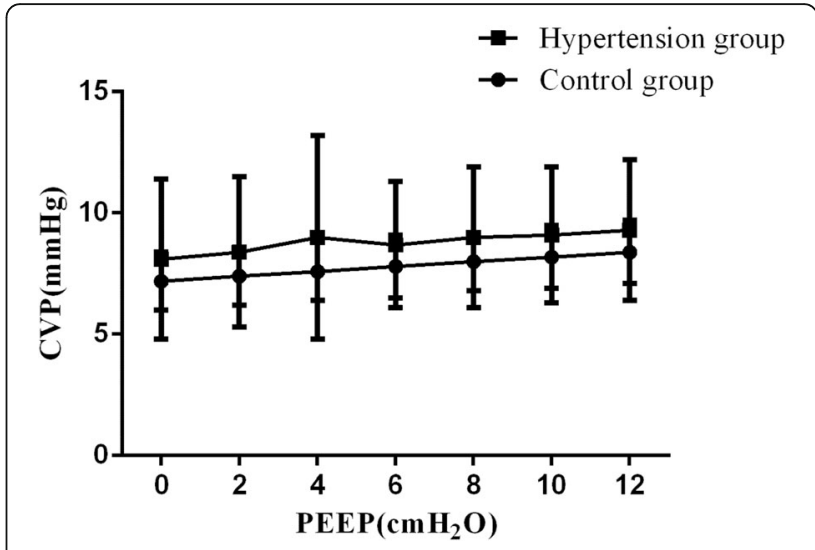

Fig. 3 Effect of different PEEP levels on central venous pressure (CVP). Data are shown as mean and standard deviation

hypertension group, when PEEP was above $4 \mathrm{~cm} \mathrm{H}_{2} \mathrm{O}$, PEEP was positively correlated with $\mathrm{HR}(r=0.333, P<$ $0.001)$ and negatively correlated with $\mathrm{ScvO}_{2}(r=-0.441$, $P<0.001)$. Using multiple linear regression analysis to control confounding factors, the correlation between PEEP and $\mathrm{HR}, \mathrm{ScvO}_{2}$ still existed (Table 5).

\section{Effects of different PEEP levels on airway pressure}

In both groups, VT, MV, and $\mathrm{SpO}_{2}$ were unaffected by PEEP, but the increase in PEEP led to an increase of Ppeak and Pmean (Table 2, Fig. 5). In addition, PEEP was positively correlated with the Ppeak $(r=0.489, P<$ $0.001)$ and Pmean $(r=0.708, P<0.001)$. Using multiple linear regression analysis to control confounding factors, a correlation between PEEP and airway pressure was still observed (Table 6).

\section{Discussion}

PEEP is applied during the end of expiration to maintain alveolar pressure above atmospheric pressure. The benefit of PEEP has been demonstrated in terms of preventing collapsed alveoli and improving oxygenation [14, 15]. However, applying PEEP may affect cardiac function and vital organ perfusion via complex mechanisms, especially for elderly hypertensives [16]. Our study found that when PEEP was below $4 \mathrm{~cm} \mathrm{H}_{2} \mathrm{O}$ in the both control

Table 4 Multiple linear regression analysis of CVP and PEEP

\begin{tabular}{llll}
\hline All subjects & Model1 & Model2 & Model3 \\
\hline CVP & & & \\
Beta & 0.150 & 0.152 & 0.174 \\
$P$ & 0.012 & 0.012 & 0.004 \\
\hline
\end{tabular}

Model 1: Adjustment for age and gender; Model 2: Adjustment for age, gender, triglyceride, total cholesterol, low density lipoprotein cholesterin, fasting plasma glucose, serum creatinine and uric acid; Model 3: Adjustment for hemoglobin, body temperature, minute ventilation volume and peripheral oxygen saturation on the basis of Model 2

CVP Central venous pressure 

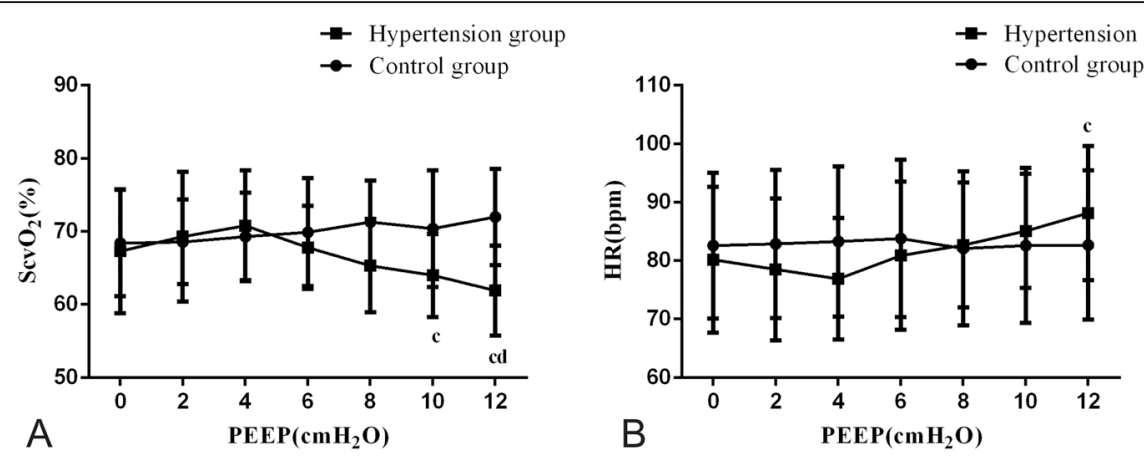

Fig. 44 Effect of different PEEP levels on central venous oxygen saturation $\left(\mathrm{ScVO}_{2}\right)$ and heart rate (HR). a: Effect of different PEEP levels on ScvO b: Effect of different PEEP levels on HR. Data are shown as mean and standard deviation. In the same group of blood pressure, ${ }^{c_{i n d i c a t e d}}$

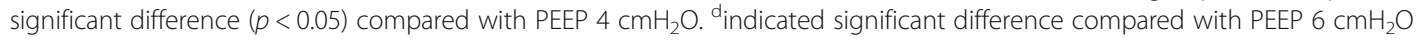

and hypertension groups, blood pressure was unaffected by PEEP. However, when PEEP was above $4 \mathrm{~cm} \mathrm{H}_{2} \mathrm{O}$, the increase in PEEP led to decreased blood pressure and PEEP was negatively correlated with blood pressure in the hypertension group. Upon control confounding factors, this negative correlation still existed. This observation may be due to diminished elasticity in elderly hypertensives' blood vessels and subsequent functional decline, suggesting a high level of PEEP would be a negative influence on hemodynamics [17].

To further study why elevated PEEP induced a drop in blood pressure, we explored the relationship between PEEP and cardiac function. As volume status was of high importance for hemodynamic instability in patients ventilated with high tidal volume and different PEEP levels, a sedative drug called midazolam was used to minimize spontaneous breathing, and tidal volume was maintained relatively constant in our study. Moreover, prior to the study, when PEEP was $0 \mathrm{~cm} \mathrm{H}_{2} \mathrm{O}$, there was no statistically significant difference in CVP between the hypertension and control groups. This result indicated that initial fluid status was similar between the two groups. During our study we controlled patients' body position and

Table 5 Multiple linear regression analysis of cardiac function and PEEP

\begin{tabular}{llll}
\hline Hypertension group $\left(\mathrm{PEEP} \geq 4 \mathrm{~cm} \mathrm{H}_{2} \mathrm{O}\right)$ & Model 1 & Model 2 & Model 3 \\
\hline $\mathrm{ScvO}_{2}$ & & & \\
$\quad$ Beta & -0.455 & -0.552 & -0.592 \\
$P$ & $<0.001$ & $<0.001$ & $<0.001$ \\
$\mathrm{HR}$ & & & \\
Beta & 0.333 & 0.345 & 0.428 \\
$P$ & $<0.001$ & $<0.001$ & $<0.001$
\end{tabular}

Model 1: Adjustment for age and gender; Model 2: Adjustment for age, gender, triglyceride, total cholesterol, low density lipoprotein cholesterin, fasting plasma glucose, serum creatinine and uric acid; Model 3: Adjustment for hemoglobin, body temperature, minute ventilation volume and peripheral oxygen saturation on the basis of Model 2

$\mathrm{ScVO}_{2}$ Central venous oxygen saturation, $\mathrm{HR}$ Heart rate infusion speed to ensure that the two groups' fluid intake was as similar as possible. We found that in both groups, VT, MV, and $\mathrm{SpO}_{2}$ were unaffected by PEEP, but increased PEEP led to an increase of CVP and airway pressure. When PEEP was raised above $4 \mathrm{~cm} \mathrm{H}_{2} \mathrm{O}$, in the hypertension group, the increase in PEEP led to a reduction in $\mathrm{ScvO}_{2}$ and an increase in HR. Furthermore, PEEP was positively correlated with HR and negatively correlated with the $\mathrm{ScvO}_{2}$. To control for confounding factors such as hemoglobin, arterial oxygen saturation and oxygen demand, we found that the correlation between PEEP and HR and $\mathrm{ScvO}_{2}$ still existed. This indicated that elevated levels of PEEP caused decreased cardiac output in elderly hypertensive patients [18].

In general, the increase in PEEP caused higher airway pressure which resulted in increased intrathoracic pressure (ITP) [19]. Elevation of CVP by increasing ITP resulted in a reduction in venous return [20]. However, for non-hypertensive subjects, the effects on increasing ITP on venous return, especially by PEEP, did not always lead to decreased cardiac output because of their strong cardiovascular regulation [21]. In elderly hypertensive patients, the thickened and stiffened vein wall caused slower venous return than that of non-hypertension subjects, which resulted in reduced right ventricular (RV) preload [22]. PEEP not only decreased RV preload by impeding systemic venous return, but also increased RV afterload in combination with high tidal volume. In our study, we used high tidal volume of $10 \mathrm{ml} / \mathrm{kg}$ body weight to maintain pulmonary oxygenation and promote carbon dioxide exhalation. High PEEP with high tidal volume led to increased end inspiratory lung volume, which was responsible for the RV afterload. VieilaardBaron [23] and Protti [24] demonstrated that afterload for RV did not influence capillary compression, but rather the end inspiratory lung volume that caused this compression and reduced the flow through the lung. As a result, the reduction in RV ejection caused by PEEP and high tidal volume decreased left ventricular filling in 

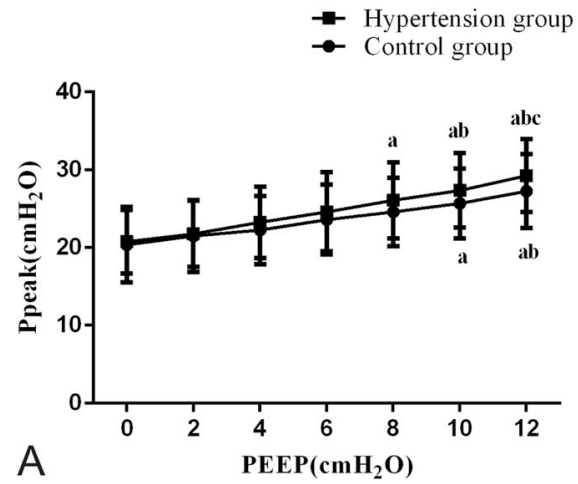

Hypertension group

Control group

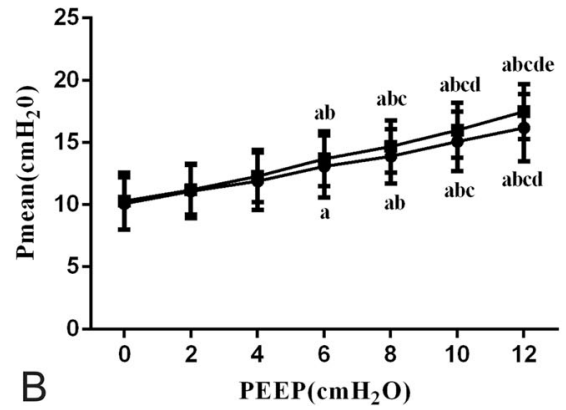

Fig. 5 Effect of different PEEP levels on peak airway pressure (Ppeak) and mean airway pressure (Pmean). a: Effect of different PEEP levels on Ppeak, b: Effect of different PEEP levels on Pmean. Data are shown as mean and standard deviation. In the same group of blood pressure, a indicated significant difference $(p<0.05)$ compared with PEEP O $\mathrm{cmH}_{2} \mathrm{O}$. ${ }^{\text {b }}$ indicated significant difference compared with $\mathrm{PEEP} 2 \mathrm{~cm} \mathrm{H}_{2} \mathrm{O}$. ${ }^{c}$ indicated significant difference compared with PEEP $4 \mathrm{cmH}_{2} \mathrm{O}$. ${ }^{\mathrm{d}}$ indicated significant difference compared with PEEP $6 \mathrm{cmH}_{2} \mathrm{O}$. ${ }^{\mathrm{e}}$ indicated significant difference compared with PEEP $8 \mathrm{cmH}_{2} \mathrm{O}$

both groups [25]. However, the hemodynamics of elderly hypertensive patients was more affected by blood volume deficiency than non- hypertensive patients. Therefore, the lower the stroke volume, the faster HR that occurs for elderly hypertensive individuals [26]. The high tidal volume was able to reduce flow through the lung and decrease left ventricular filling, so it was also used to highlight the difference in the response to hypovolemia between the two groups in the present study.

In our study, we found that the increase in PEEP led to an increase in CVP but a decrease in cardiac output. Studies assessing fluid status have shown that CVP monitoring is as effective, and safer, than more invasive means such as pulmonary artery occlusion pressure [27]. It is clear, however, that CVP does not tell the entire story, as patients with positive pressure ventilation may have high CVP, but reduced circulating volume [28]. Currently, many scholars have not advocated the use of CVP to predict changes in pre-cardiac load in mechanical ventilation $[29,30]$. However, accurate measurement

Table 6 Multiple linear regression analysis of airway pressure and PEEP

\begin{tabular}{clll}
\hline All subjects & Model1 & Model2 & Model3 \\
\hline Ppeak & & & \\
Beta & 0.489 & 0.514 & 0.515 \\
$P$ & $<0.001$ & $<0.001$ & $<0.001$ \\
Pmean & & & \\
Beta & 0.713 & 0.740 & 0.744 \\
$P$ & $<0.001$ & $<0.001$ & $<0.001$ \\
\hline
\end{tabular}

Model 1: Adjustment for age and gender; Model 2: Adjustment for age, gender, triglyceride, total cholesterol, low density lipoprotein cholesterin, fasting plasma glucose, serum creatinine and uric acid; Model 3: Adjustment for hemoglobin, body temperature, minute ventilation volume and peripheral oxygen saturation on the basis of Model 2

Ppeak Peak airway pressure, Pmean Mean airway pressure of cardiac output, such as by SwanGanz catheter and cardiac color ultrasound requires advanced instrumentation and incurs greater cost [31]. Recent studies have found that $\mathrm{ScvO}_{2}$ can be used to evaluate the condition of left cardiac ejection, which is simple and reliable and can be used in clinical application [18]. A study by Lanspa et al. reported that assessment of cardiac function often relied on $\mathrm{ScvO}_{2}$, with higher $\mathrm{ScvO}_{2}$ corresponding with increased cardiac output [32]. As such, our study used $\mathrm{ScvO}_{2}$ to reflect left cardiac ejection.

For elderly hypertensive patients, this study showed that PEEP of approximately $4 \mathrm{~cm} \mathrm{H}_{2} \mathrm{O}$ could have maximal impact on improving oxygenation, and minimize its impact on hemodynamics. However, due to the limited patient source, the appropriate PEEP value setting should be confirmed by the large sample multicenter clinical study.

\section{Conclusions}

Traditional static index CVP cannot accurately reflect changes in cardiac preload with positive pressure ventilation, though $\mathrm{ScvO}_{2}$ shows obvious advantages, which can be used to predict cardiac preload under mechanical ventilation. For elderly patients with hypertension, low levels of PEEP have less effect on blood pressure and cardiac output, while higher levels of PEEP can significantly affect blood pressure and cardiac output. Therefore, the effects of PEEP on the hemodynamics of elderly patients with hypertension should be taken into consideration.

\section{Abbreviations}

ANOVA: Analysis of variance; CVP: Central venous pressure; DBP: Diastolic blood pressure; $\mathrm{DO}_{2}$ : Oxygen delivery; FPG: Fasting plasma glucose; HB: Hemoglobin; HR: Heart rate; ITP: Increased intrathoracic pressure; LDLC: low density lipoprotein cholesterin; MABP: Mean arterial blood pressure; MV: Minute ventilation volume; PEEP: Positive end expiratory pressure; Pmean: Mean airway pressure; Ppeak: Peak airway pressure; PVR: Pulmonary 
vascular resistance; RV: Right ventricular; SBP: Systolic blood pressure; Scr: Serum creatinine; $\mathrm{ScvO}_{2}$ : Central venous oxygen saturation; $\mathrm{SpO}_{2}$ : Peripheral oxygen saturation; T: Body temperature; TC: Total cholesterol; TG: Triglyceride; UA: Uric acid; $\mathrm{VO}_{2}$ : Consumption

\section{Acknowledgements}

We would like to thank all of our colleagues who recruited and treated the patients.

\section{Authors' contributions}

LZ designed the experiment, conducted the experiment, analyzed the data and wrote the manuscript. GC designed the experiment, conducted the experiment and wrote the manuscript. ZX and QW investigated the patients and collected the data. QY investigated the patients and analyzed the data. CC designed the experiment, funded the study and wrote the manuscript. LZ, GC, ZX, QW, QY and CC contributed to drafting and revision of the manuscript and approval of the final version to be submitted for consideration for publication.

\section{Funding}

This study was supported by Nation and Fujian Province's Key Clinical Specialty Discipline Construction Program, Fujian Medical University Union Hospital Project(2015-GJLN-3-08) and the Fujian Provincial Science and Technology Guiding Project (No.2017Y0041,2018Y0033).

\section{Availability of data and materials}

The datasets used and/or analysed during the current study are available from the corresponding author on reasonable request.

\section{Ethics approval and consent to participate}

The study was approved by the Ethics Committee of Union Hospital Affiliated to Fujian Medical University. Chinese clinical trial registration number is ChiCTR-ROC-17012873. All procedures involving human participants were in accordance with the ethical standards of the institutional and/ or national research committee and with the 1964 Helsinki declaration and its later amendments or comparable ethical standards.

All subjects signed informed consent to participate in the study.

\section{Consent for publication}

Consent for publication was not required because all patient data were anonymised.

\section{Competing interests}

The authors declare that they have no competing interests.

\section{Author details}

${ }^{1}$ Department of Geriatrics, Union Hospital, Fujian Medical University, Fuzhou, Fujian 350001, People's Republic of China. ${ }^{2}$ Department of Critical Care Medicine, Union Hospital, Fujian Medical University, Fuzhou, Fujian 350001, People's Republic of China. ${ }^{3}$ Department of Neurology, Union Hospital, Fujian Medical University, Fuzhou, Fujian 350001, People's Republic of China.

\section{Received: 28 November 2017 Accepted: 18 October 2019} Published online: 27 November 2019

\section{References}

1. Wu L, He Y, Jiang B, Sun D, Wang J, Liu M, Yang S, Wang Y. Trends in prevalence, awareness, treatment and control of hypertension during 2001-2010 in an urban elderly population of China. PLoS One. 2015;10(8): e0132814.

2. Kaiser EA, Lotze U, Schäfer HH. Increasing complexity: which drug class to choose for treatment of hypertension in the elderly? Clin Interv Aging. 2014; 9:459-75.

3. American Heart Association Statistics Committee and Stroke Statistics Subcommittee. Heart disease and stroke statistics--2015 update: a report from the American Heart Association. Circulation. 2015;131(4):e29-322.

4. Lionakis N, Mendrinos D, Sanidas E, Favatas G, Georgopoulou M. Hypertension in the elderly. World J Cardiol. 2012;4(5):135-47.

5. Buford TW. Hypertension and Aging. Ageing Res Rev. 2016;26:96-111.

6. Mikor A, Trásy D, Németh MF, Osztroluczki A, Kocsi S, Kovács I, Demeter G, Molnár Z. Continuous central venous oxygen saturation assisted intraoperative hemodynamic management during major abdomina surgery: a randomized, controlled trial. BMC Anesthesiol. 2015;15:82.

7. He H, Long Y, Liu D, Wang X, Zhou X. Clinical classification of tissue perfusion based on the central venous oxygen saturation and the peripheral perfusion index. Crit Care. 2015;19(1):330.

8. Laine GA, Hu BY, Wang S, Thomas Solis R, Reul GJ Jr. Isolated high lactate or low central venous oxygen saturation after cardiac surgery and association with outcome. J Cardiothorac Vasc Anesth. 2013;27(6):1271-6.

9. Burša F, Pleva L. Anaerobic metabolism associated with traumatic hemorrhagic shock monitored by microdialysis of muscle tissue is dependent on the levels of hemoglobin and central venous oxygen saturation: a prospective, observational study. Scand J Trauma Resusc Emerg Med. 2014;22:11.

10. Chandy D, Aronow WS, Banach M. Current perspectives on treatment of hypertensive patients with chronic obstructive pulmonary disease. Integr Blood Press Control. 2013;6:101-9.

11. Palatini P, Casiglia E, Gąsowski J, Głuszek J, Jankowski P, Narkiewicz K, Saladini F, Stolarz-Skrzypek K, Tikhonoff V, Van Bortel L, Wojciechowska W, Kawecka-Jaszcz K. Arterial stiffness, central hemodynamics, and cardiovascular risk in hypertension. Vasc Health Risk Manag. 2011;7:725-39.

12. Vargas M, Sutherasan $Y$, Gregoretti C, Pelosi P. PEEP role in ICU and operating room: from pathophysiology to clinical practice. ScientificWorldJournal. 2014;2014:852356.

13. Hypertension Study Group. Prevalence, awareness, treatment and control of hypertension among the elderly in Bangladesh and India: a multicentre study. Bull World Health Organ. 2001;79(6):490-500.

14. Garnero A, Tuxen D, Corno G, Durand-Gasselin J, Hodgson C, Arnal J-M. Dynamics of end expiratory lung volume after changing positive endexpiratory pressure in acute respiratory distress syndrome patients. Crit Care. 2015;19(1):340.

15. Nespoulet H, Rupp T, Bachasson D, Tamisier R, Wuyam B, Lévy P, Verges S Positive expiratory pressure improves oxygenation in healthy subjects exposed to hypoxia. PLoS One. 2013;8(12):e85219.

16. Gattinoni L, Collino F, Maiolo G, Rapetti F, Romitti F, Tonetti T, Vasques F, Quintel M. Positive end-expiratory pressure: how to set it at the individual level. Ann Transl Med. 2017;5(14):288

17. Denker MG, Cohen DL. What is an appropriate blood pressure goal for the elderly: review of recent studies and practical recommendations. Clin Interv Aging. 2013;8:1505-17.

18. Kapoor PM, Dhawan I, Jain P, Chowdhury U. Lactate, endothelin, and central venous oxygen saturation as predictors of mortality in patients with tetralogy of Fallot. Ann Card Anaesth. 2016;19(2):269-76.

19. Luecke T, Pelosi P. Clinical review: positive end-expiratory pressure and cardiac output. Crit Care. 2005;9(6):607-21.

20. Guyton AC, Lindsey AW, Abernathy $B$, et al. Venous return at various right atrial pressures and the normal venous return curve. Am J Phys. 1957;189: 609-15.

21. Fares WH, Carson SS. The relationship between positive end expiratory pressure and cardiac index in patients with acute respiratory distress syndrome. J Crit Care. 2013;28(6):10

22. Orde SR, Behfar A, Stalboerger PG, Barros-Gomes S, Kane GC, Oh JK. Effect of positive end-expiratory pressure on porcine right ventricle function assessed by speckle tracking echocardiography. BMC Anesthesiol. 2015;15:49.

23. Vieillard-Baron A, Loubieres Y, Schmitt JM, Page B, Dubourg O, Jardin F. Cyclic changes in right ventricular output impedance during mechanical ventilation. J Appl Physiol (1985). 1999;87(5):1644-50.

24. Protti A, Andreis DT, Monti M, Santini A, Sparacino CC, Langer T, Votta E, Gatti S, Lombardi L, Leopardi O, Masson S, Cressoni M, Gattinoni L. Lung stress and strain during mechanical ventilation: any difference between statics and dynamics? Crit Care Med. 2013;41(4):1046-55.

25. Rankin JS, Olsen CO, Arentzen CE, et al. The effects of airway pressure on cardiac function in intact dogs and man. Circulation. 1982;66:108-20.

26. Yu K, Nakashima T, Iseri T, Yonetani C, Ueda K, Fujimoto Y, Kato S. The impact of inspiratory pressure on stroke volume variation and the evaluation of indexing stroke volume variation to inspiratory pressure under various preload conditions in experimental animals. J Anesth. 2015:29(4):515-21.

27. Li D-k, Wang X-t, Liu D-w. Association between elevated central venous pressure and outcomes in critically ill patients. Ann Intensive Care. 2017;7:83.

28. House AA, Haapio M, Lentini P, Bobek I, de Cal M, Cruz DN, Virzì GM, Carraro R, Gallo G, Piccinni P, Ronco C. Volume Assessment in Mechanically Ventilated Critical Care Patients Using Bioimpedance Vectorial Analysis, Brain 
Natriuretic Peptide, and Central Venous Pressure. Int J Nephrol. 2011;2011: 413760.

29. Kumar D, Ahmed SM, Ali S, Ray U, Varshney A, Doley K. Correlation between central venous pressure and peripheral venous pressure with passive leg raise in patients on mechanical ventilation. Indian J Crit Care Med. 2015; 19(11):648-54.

30. Sundaram SC, Salins SR, Kumar AN, Korula G. Intra-Operative Fluid Management in Adult Neurosurgical Patients Undergoing Intracranial Tumour Surgery: Randomised control trial comparing pulse pressure variance (PPV) and central venous pressure (CVP). J Clin Diagn Res. 2016; 10(5):UC01-5

31. Pinsky MR, editor. Functional Hemodynamic Monitoring. Crit Care Clin. 2015; 31(1):89-111.

32. Lanspa MJ, Pittman JE, Hirshberg EL, Wilson EL, Olsen T, Brown SM, Grissom CK. Association of left ventricular longitudinal strain with central venous oxygen saturation and serum lactate in patients with early severe sepsis and septic shock. Crit Care. 2015;19(1):304.

\section{Publisher's Note}

Springer Nature remains neutral with regard to jurisdictional claims in published maps and institutional affiliations.

Ready to submit your research? Choose BMC and benefit from:

- fast, convenient online submission

- thorough peer review by experienced researchers in your field

- rapid publication on acceptance

- support for research data, including large and complex data types

- gold Open Access which fosters wider collaboration and increased citations

- maximum visibility for your research: over $100 \mathrm{M}$ website views per year

At $\mathrm{BMC}$, research is always in progress.

Learn more biomedcentral.com/submissions 